УДК 338.24

DOI 10.18413/2687-0932-2020-47-3-522-532

\title{
Оценка значимости угроз экономической безопасности для ведущих отечественных предприятий черной металлургии
}

\author{
И.Л. Рябков, Н.Н. Яшалова \\ Череповецкий государственный университет, \\ Россия, 162600, г. Череповец, ул. Луначарского, 5 \\ E-mail: il.ryabkov@gmail.com,natalij2005@mail.ru
}

\begin{abstract}
Аннотация
В статье представлено теоретическое и практическое обоснование системного подхода для оценки значимости угроз экономической безопасности, характерных для предприятий черной металлургии. Обоснована необходимость проведения постоянного мониторинга внешних и внутренних факторов, влияющих на эту оценку. В результате моделирования значимости различных групп угроз экономической безопасности авторы пришли к выводу, что для металлургических предприятий наиболее важными эндогенными угрозами являются финансово-экономические, техникотехнологические и маркетинговые, среди экзогенных - внутри- и внешнерыночные угрозы.
\end{abstract}

Ключевые слова: экономическая безопасность, черная металлургия, угрозы, моделирование, оценка, математическая статистика.

Благодарности: исследование выполнено при финансовой поддержке Российского фонда фундаментальных исследований (РФФИ) в рамках научного проекта № 19-310-90004.

Для цитирования: Рябков И.Л., Яшалова Н.Н. 2020. Оценка значимости угроз экономической безопасности для ведущих отечественных предприятий черной металлургии. Экономика. Информатика. 47 (3): 522-532. DOI 10.18413/2687-0932-2020-47-3-522-532.

\section{Assessment of the significance of threats to economic security for leading domestic ferrous metallurgy enterprises}

\author{
I.L. Ryabkov, N.N. Yachalova \\ Cherepovets State University, \\ 5 Lunacharsky str., Cherepovets, 162600 , Russia \\ E-mail: il.ryabkov@gmail.com, natalij2005@mail.ru
}

\begin{abstract}
The article presents a theoretical and practical justification of the system approach for assessing the significance of threats to economic security that are characteristic of ferrous metallurgy enterprises. The necessity of constant monitoring of external and internal factors affecting this assessment is justified. To build an adequate system of threshold values for economic security indicators, we used a set of mathematical and expert methods that allow us to divide the state classes even taking into account the volatility of the indicators accepted for consideration. As a result of modeling the significance of various groups of threats to economic security, we came to the conclusion that the most important endogenous threats for metallurgical enterprises are financial, economic, technical, technological and marketing, among exogenous-internal and external market threats. Knowledge of the range of main threats and the degree of their impact on ferrous metallurgy enterprises will help to create a comprehensive fuzzy-logical model for assessing economic security and will allow you to make forecast scenario plans for business development, knowing approximate trends.
\end{abstract}

Keywords: economic security, ferrous metallurgy, threats, modeling, estimation, mathematical statistics.

Acknowledgements: the reported study was funded by RFBR according to the research project № 19-31090004.

For citation: Ryabkov I.L., Yachalova N.N. 2020. Assessment of the significance of threats to economic security for leading domestic ferrous metallurgy enterprises. Economics. Information technologies. 47 (3): 522-532 (in Russian). DOI 10.18413/2687-0932-2020-47-3-522-532. 


\section{Введение}

В течение современного периода развития (с начала 2000-х гг.) предприятия отечественной чёрной металлургии систематически сталкиваются с рядом факторов, оказывающих серьёзное влияние на экономическую безопасность этого вида экономической деятельности. Актуальность исследования заключается в том, что оценка состояния экономической безопасности является важнейшим процессом для обеспечения наиболее эффективного функционирования и развития предприятий чёрной металлургии, имеющих большой удельный вес в экономике России.

Комплексная оценка состояния экономической безопасности промышленного предприятия требует наличия системы индикаторов, характеризующих угрозы для хозяйствующих субъектов. В настоящей работе под «индикатором» будем понимать числовой показатель, который показывает динамику того или иного экономического процесса. Индикаторы экономической безопасности обеспечивают своевременный мониторинг состояния широкого круга внешних и внутренних процессов, связанных с деятельностью предприятия.

Индикаторы, характеризующие внутренние процессы предприятия, отражают уровень развития производственно-сбытовых процессов, сбалансированность финансов, экономическую устойчивость, результаты социальной политики предприятия. Важно, чтобы система индикаторов экономической безопасности описывала специфику не только внутренних процессов предприятия, но и внешних. К ним относятся макроэкономические процессы, а также процессы взаимодействия с органами власти, конкурентами, социумом. С одной стороны, это позволит обеспечить комплексность оценки состояния экономической безопасности предприятия, с другой стороны - осложнит сбор и интерпретацию статистической информации [Симонов и др., 2018].

В практике российских исследований наблюдается несколько подходов к формированию системы индикаторов экономической информации в зависимости от объекта исследования. Наиболее известной в научном сообществе является система из двадцати двух индикаторов, разработанная С.Ю. Глазьевым для мониторинга экономической безопасности страны, охватывающая финансовую, экономическую, производственную, социальную сферы жизни общества [Глазьев, 1997]. Отдельным достоинством системы являются рассчитанные пороговые значения для каждого индикатора, при превышении которых возникает возможность реализации тех или иных угроз экономической безопасности.

Несколько позже под руководством В.К. Сенчагова была разработана система индикаторов, охватывающая шесть сфер деятельности государства [Сенчагов и др., 2011]. На объемном массиве макроэкономических показателей (порядка 150 рядов) в 2008 г. был сформирован список из тридцати шести индикаторов экономической безопасности. Избранные индикаторы экономической безопасности обладают свойствами количественного отражения угроз, высокой чувствительности и взаимной синергии. В качестве методов расчета пороговых значений индикаторов использовались: расчетно-нормативный, метод аналогий, опрос экспертов.

В целях выявления угроз и обеспечения состояния экономической безопасности в настоящее время рекомендована система из сорока индикаторов [Указ, 2017], охватывающая все сферы экономической деятельности. Особенностью данной системы является ее универсальность - при некотором уточнении перечня индикаторов её можно использовать для оценки состояния экономической безопасности объектов различного масштаба. Рассмотренные системы индикаторов обладают едиными недостатками, а именно отсутствие правил учета взаимного влияния индикаторов и алгоритма расчета комплексной оценки экономической безопасности. 


\section{Материалы и методы}

Непрерывный характер диагностики экономической безопасности предприятия требует регулярной актуализации данных индикаторов. Приоритетными источниками широкого спектра экономической информации для построения системы индикаторов экономической безопасности металлургических предприятий будут являться: федеральная служба государственной статистики, статистика мировых экономических организаций (Международный валютный фонд, ассоциация металлопроизводителей WorldSteel), отраслевые аналитические агентства (Deloitte), квартальные и годовые финансовые отчеты компаний. Объективный характер экономической информации, использующейся для формирования индикаторов экономической безопасности, позволяет привлекать мнение экспертов лишь на стадии интерпретации полученных результатов.

Приведем перечень доступных или поддающихся вычислению индикаторов экономической безопасности, характерных в том числе для металлургических предприятий (табл. 1), и присутствующих в перечисленных источниках экономической информации.

Таблица 1

Table 1

Перечень индикаторов для оценки экономической безопасности металлургических предприятий

List of indicators for assessing the economic security of metallurgical enterprises

\begin{tabular}{|c|c|}
\hline $\begin{array}{l}\text { Группа } \\
\text { индикаторов } \\
\text { экономической } \\
\text { безопасности }\end{array}$ & Индикаторы \\
\hline \multicolumn{2}{|r|}{ ОТНОСЯЩИЕСЯ К ВНЕШНИМ УГРОЗАМ } \\
\hline $\begin{array}{l}\text { Внешне- } \\
\text { рыночные }\end{array}$ & $\begin{array}{l}\text { Макроэкономические показатели (ВВП, курсы валют, ключевая процентная ставка, } \\
\text { торговый баланс, уровень инфляции в ключевых мировых регионах), темп роста } \\
\text { производства и потребления стали на ключевых мировых рынках, динамика } \\
\text { изменения мировых цен на сырье и металлопрокат, количество действующих } \\
\text { ограничений международной торговли, оценка возможности наложения } \\
\text { санкционных мер, способных нанести ущерб деятельности компании. }\end{array}$ \\
\hline $\begin{array}{l}\text { Внутри- } \\
\text { рыночные }\end{array}$ & $\begin{array}{l}\text { Уровень производства и потребления стали в России, динамика объемов } \\
\text { экспорта и импорта стали, динамика изменения российских цен на сырье и } \\
\text { металлопрокат, доля присутствия на внутреннем рынке, доля выпуска } \\
\text { продукции с высокой добавленной стоимостью, оценка возможности усиления } \\
\text { налоговой нагрузки, повышение ключевой ставки, снижение количества } \\
\text { предоставляемых кредитов в смежных отраслях }\end{array}$ \\
\hline $\begin{array}{l}\text { Социально- } \\
\text { экономические } \\
\text { или } \\
\text { региональные }\end{array}$ & $\begin{array}{l}\text { Индикаторы экономической безопасности, рекомендованные Стратегией } \\
\text { экономической безопасности Российской Федерации применительно к } \\
\text { субъектам страны. Индикаторы рассчитываются Федеральной службой } \\
\text { государственной статистики. }\end{array}$ \\
\hline \multicolumn{2}{|r|}{$\begin{array}{c}\text { ОТНОСЯЩИЕСЯ К УГРОЗАМ, ПРОЯВЛЯЮЩИМСЯ НА ВНЕШНЕМ } \\
\text { И ВНУТРЕННЕМ УРОВНЯХ }\end{array}$} \\
\hline Экологические & $\begin{array}{l}\text { Динамика использования невозобновляемых ресурсов, темп роста затрат на } \\
\text { экологические инвестиции и природоохранные меры по виду экономической } \\
\text { деятельности, динамика доли объемов выбросов вредных веществ в атмосферу } \\
\text { и водные объекты по региону, количество допущенных аварийных выбросов, } \\
\text { количество отходов производства, прошедших переработку, соответствие } \\
\text { использования оборудования перечню НдТ. }\end{array}$ \\
\hline $\begin{array}{l}\text { Информацион- } \\
\text { ные }\end{array}$ & $\begin{array}{l}\text { Доля сотрудников, занятых в работе информационного подразделения компании } \\
\text { (разработка проектов применения данных в бизнес-проектах, защита } \\
\text { коммерческой тайны, обеспечение информационной безопасности), доля от } \\
\text { общих затрат компании, направляемая на поддержание деятельности и } \\
\text { инвестиции в информационное подразделение. }\end{array}$ \\
\hline
\end{tabular}




\begin{tabular}{|c|c|}
\hline $\begin{array}{c}\text { Группа } \\
\text { индикаторов } \\
\text { экономической } \\
\text { безопасности } \\
\end{array}$ & Индикаторы \\
\hline \multicolumn{2}{|r|}{ ОТНОСЯЩИЕСЯ К ВНУТРЕННИМ УГРОЗАМ } \\
\hline $\begin{array}{l}\text { Производ- } \\
\text { ственно- } \\
\text { сбытовые }\end{array}$ & $\begin{array}{l}\text { Динамика объема производства, доля продукции с высокой добавленной } \\
\text { стоимостью в портфеле заказов, ценовое лидерство в сравнении с конкурентами, } \\
\text { доля продаж на премиальные рынки, объем просроченной дебиторской } \\
\text { задолженности, состояние основных фондов, уровень загрузки } \\
\text { производственных мощностей, фондоодача, производительность труда, } \\
\text { динамика себестоимости производства продукции, скорость оборота } \\
\text { материалов, объем инвестиций в основные активы, процент претензионной } \\
\text { продукции, данные удовлетворенности клиентов. }\end{array}$ \\
\hline $\begin{array}{l}\text { Финансово- } \\
\text { экономические }\end{array}$ & $\begin{array}{l}\text { Рентабельность активов, рентабельность собственного и совокупного } \\
\text { капиталов, темпы роста выручки и прибыли, прибыль EBITDA, свободный } \\
\text { денежный поток } F C F \text {, скорость оборачиваемости дебиторской и кредиторской } \\
\text { задолженностей, отношение чистого долга к свободному денежному потоку, } \\
\text { наличие отрицательного финансового результата, коэффициенты ликвидности, } \\
\text { налоговая нагрузка, темпы роста расходов. }\end{array}$ \\
\hline Кадровые & $\begin{array}{l}\text { Коэффициент кадровой обеспеченности, доля сотрудников, соответствующих } \\
\text { требованиям должностной инструкции, доля управленческого персонала, доля } \\
\text { работников предпенсионного возраста, коэффициент текучести кадров, } \\
\text { коэффициент соответствия заработной платы среднеотраслевым значениям, } \\
\text { коэффициент соответствия условий труда нормам, коэффициент соответствия } \\
\text { технике безопасности, коэффициент количества учтенных несчастных случаев } \\
\text { на производстве LTIFR. }\end{array}$ \\
\hline
\end{tabular}

Составлено авторами

Руководствуясь принципом комплексного анализа сфер деятельности металлургических предприятий, подберем для каждой группы значимых угроз (табл. 2) до трех индикаторов экономической безопасности. Именно по этому перечню индикаторов в дальнейшем предполагается проведение мониторинга их динамики для расчета пороговых значений.

Таблица 2

Table 2

Соответствие индикаторов и значимых групп угроз

экономической безопасности металлургических предприятий

Compliance of indicators and significant threat groups economic security of metallurgical enterprises

\begin{tabular}{|c|c|c|}
\hline $\begin{array}{c}\text { Группа угроз } \\
\text { экономической } \\
\text { безопасности }\end{array}$ & $\begin{array}{l}\text { Вид угрозы экономической } \\
\text { безопасности }\end{array}$ & Индикаторы экономической безопасности \\
\hline $\begin{array}{l}\text { Политико- } \\
\text { экономические } \\
\text { (мегауровень) }\end{array}$ & $\begin{array}{l}\text { Угроза действий органов } \\
\text { власти различных стран. }\end{array}$ & $\begin{array}{l}\text { Доля иностранной валюты по отношению к } \\
\text { рублевой массе, квотирование объемов } \\
\text { внешнеторговых потоков, количество введенных } \\
\text { санкционных ограничений. }\end{array}$ \\
\hline \multirow{5}{*}{$\begin{array}{l}\text { Внешне- } \\
\text { рыночные } \\
\text { (международный } \\
\text { уровень) }\end{array}$} & $\begin{array}{l}\text { Угроза снижения спроса на } \\
\text { сталь. }\end{array}$ & $\begin{array}{l}\text { Динамика абсолютного спроса в России и мире, } \\
\text { потребление стали на душу населения, загрузка } \\
\text { производственных мощностей. }\end{array}$ \\
\hline & $\begin{array}{l}\text { Угроза снижения цен на } \\
\text { сталь. }\end{array}$ & Динамика цен на сталь на мировых рынках. \\
\hline & $\begin{array}{l}\text { Угроза роста цен на сырье, } \\
\text { топливо, услуги. }\end{array}$ & $\begin{array}{l}\text { Динамика цен на металлургическое сырье по } \\
\text { видам, на тарифы монополий. }\end{array}$ \\
\hline & Угроза девальвации валют. & Изменение курсов основных валют. \\
\hline & $\begin{array}{l}\text { Угроза колебания } \\
\text { процентных ставок. }\end{array}$ & Динамика изменения ключевой ставки ЦБ РФ. \\
\hline
\end{tabular}




\begin{tabular}{|c|c|c|}
\hline $\begin{array}{c}\text { Группа угроз } \\
\text { экономической } \\
\text { безопасности }\end{array}$ & $\begin{array}{c}\text { Вид угрозы экономической } \\
\text { безопасности }\end{array}$ & Индикаторы экономической безопасности \\
\hline $\begin{array}{l}\text { Политические } \\
\text { (международный } \\
\text { уровень) }\end{array}$ & $\begin{array}{l}\text { Угрозы введения } \\
\text { ограничений в } \\
\text { международной торговле. }\end{array}$ & $\begin{array}{l}\text { Количество ограничений } \\
\text { торговли (количество стран илинародной } \\
\text { оценка потерянной прибыли. }\end{array}$ \\
\hline \multirow[t]{2}{*}{$\begin{array}{l}\text { Внутрирыночные } \\
\text { (макро- } \\
\text { экономический } \\
\text { уровень) }\end{array}$} & Усиление конкуренции. & $\begin{array}{l}\text { Доля присутствия на внутреннем } \\
\text { динамика ценового пре, } \\
\text { производимой продукция с ств, доля } \\
\text { добавленной стоимостью. }\end{array}$ \\
\hline & $\begin{array}{l}\text { банков, } \\
\text { цих } \\
\text { ия. }\end{array}$ & 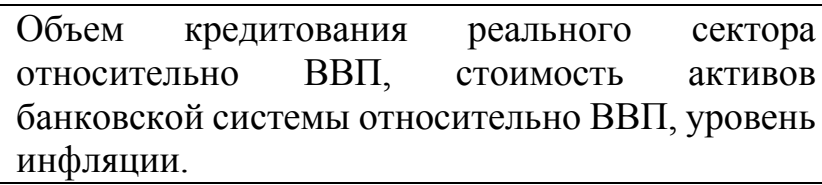 \\
\hline $\begin{array}{l}\text { Нормативно- } \\
\text { законодательные } \\
\text { (макро- } \\
\text { экономический } \\
\text { уровень) }\end{array}$ & говое & $\begin{array}{l}\text { Эффективные ставки налогов на прибыль, } \\
\text { имущество для предприятий, доля налоговых } \\
\begin{array}{l}\text { отчислений от нераспределенной прибыли } \\
\text { предприятия. }\end{array}\end{array}$ \\
\hline $\begin{array}{l}\text { Потребительские } \\
\text { (макро- } \\
\text { экономический } \\
\text { уровень) }\end{array}$ & ти & $\begin{array}{l}\text { Уровень доступности кредитования предприятий } \\
\text { обрабатывающей промышленности, объем } \\
\text { просроченной дебиторской задолженности. }\end{array}$ \\
\hline $\begin{array}{l}\text { Социальные } \\
\text { (мезо- } \\
\text { экономический } \\
\text { уровень) }\end{array}$ & B & $\begin{array}{l}\text { Использование перечня индикаторов угроз, } \\
\text { рекомендованных Стратегией экономической } \\
\text { безопасности России. }\end{array}$ \\
\hline $\begin{array}{l}\text { Информационные } \\
\text { (мезо- и микро- } \\
\text { экономический } \\
\text { уровни) }\end{array}$ & $\begin{array}{l}\text { Угрозы информационной } \\
\text { безопасности }\end{array}$ & $\begin{array}{l}\text { Количество значимых информационных атак, } \\
\text { затраты на инвестиции и поддержание ИТ- } \\
\text { инфраструктуры и проектов, доля сотрудников } \\
\text { ИТ-департамента от общей численности } \\
\text { персонала. }\end{array}$ \\
\hline $\begin{array}{l}\text { Экологические } \\
\text { (мезо- и микро- } \\
\text { экономический } \\
\text { уровни) }\end{array}$ & & $\begin{array}{l}\text { Динамика использования невозобновляемых } \\
\text { ресурсов, объем выбросов, объем отходов, } \\
\text { размер инвестиций и бюджета природоохранной } \\
\text { деятельности. }\end{array}$ \\
\hline $\begin{array}{l}\text { Инвестиционные } \\
\text { (микро- } \\
\text { экономический } \\
\text { уровень) }\end{array}$ & 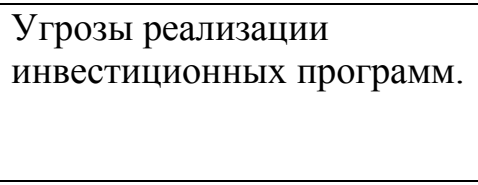 & $\begin{array}{l}\text { Объем инвестиций в основные средства, средний } \\
\text { срок реализации инвестиционного проекта. }\end{array}$ \\
\hline \multirow{2}{*}{$\begin{array}{l}\text { Финансово- } \\
\text { управленческие } \\
\text { (микро- } \\
\text { экономический } \\
\text { уровень) }\end{array}$} & $\begin{array}{l}\text { Угроза роста издержек и } \\
\text { неэффективного } \\
\text { управления запасами. }\end{array}$ & $\begin{array}{l}\text { Доля издержек от выручки, доля } \\
\text { непроизводственных расходов, скорость оборота } \\
\text { запасов. }\end{array}$ \\
\hline & $\begin{array}{l}\text { Угроза возникновения } \\
\text { мошеннических и }\end{array}$ & Уровень экономической преступности в России. \\
\hline $\begin{array}{l}\text { Производственно- } \\
\text { сбытовые (микро- } \\
\text { экономический } \\
\text { уровень) }\end{array}$ & $\begin{array}{l}\text { становки } \\
\text { и. }\end{array}$ & $\begin{array}{l}\text { Финансово-экономические индикаторы, } 3 / \Pi \\
\text { сотрудников относительно среднеотраслевого и } \\
\text { среднерегионального уровней. }\end{array}$ \\
\hline $\begin{array}{l}\text { Управленческие } \\
\text { (мини- } \\
\text { экономический } \\
\text { уровень) }\end{array}$ & $\begin{array}{l}\text { Угрозы охраны тр } \\
\text { промышленной } \\
\text { безопасности. }\end{array}$ & $\begin{array}{l}\text { Динамика количества учтенных несчастных } \\
\text { случаев на производстве LTIFR, количество } \\
\text { проведенных обучений сотрудников, объем } \\
\text { затрат на охрану безопасности труда. }\end{array}$ \\
\hline
\end{tabular}

Составлено авторами 
Система пороговых значений индикаторов экономической безопасности является важным инструментом мониторинга и анализа состояния для любого объекта исследования. В общем виде пороговые значения индикаторов экономической безопасности - это предельные количественные значения индикаторов, характеризующие переход исследуемого объекта в качественно иное состояние.

Существует несколько взглядов отечественных исследователей на природу пороговых значений индикаторов экономической безопасности:

- В.С. Сенчагов и Е.А. Иванов трактуют пороговые значения индикаторов как границы опасного состояния экономической безопасности, при котором происходит нарушение нормальной деятельности объекта исследования, проявляется его незащищенность от воздействия внешних угроз [Сенчагов и др., 2015];

- О.А. Магомедов отмечает, что пороговые значения являются границами состояния экономической безопасности, за которыми происходит комплексное ухудшение производственных и финансово-экономических результатов деятельности, ослабление темпов устойчивого развития, увеличение затрат на восстановление безопасного состояния [Магомедов, 2008];

- А.В. Калина, И.П. Савельева подразумевают под пороговыми значениями индикаторов их ключевые значения, разделяющие классы комплексных состояний экономической безопасности (нормальное, переходное, кризисное) [Калина и др., 2014].

При формировании системы пороговых значений индикаторов исследователи также придерживаются разных подходов:

- введение единственного порогового значения, разделяющего два класса состояния экономической безопасности (целевой и с проявлением угроз);

- дополнение первого подхода промежуточными подуровнями, характеризующими стадии состояния экономической безопасности;

- создание многоуровневой системы пороговых значений для каждого индикатора, причем количество возможных классов состояний будет равняться числу пороговых значений, увеличенному на единицу.

В соответствии со спецификой рыночных стратегий металлургических предприятий в настоящем исследовании предлагается определять три класса состояний экономической безопасности. Каждая из рассмотренных рыночных стратегий российских производителей металлопроката предлагает программы мероприятий развития в среднесрочном периоде. Для обеспечения реализации программ развития необходимо достижение такого состояния экономической безопасности, которое бы позволило не только поддерживать текущее функционирование предприятия и иметь достаточный резерв для отражения возможных угроз, но и иметь достаточный источник инвестиционной активности. Нижней границей такого целевого состояния будут являться первые пороговые значения индикаторов.

Следующий класс состояний экономической безопасности предприятия, при котором индикаторы в целом принимают свои значения ниже целевого, называется переходным. Его специфика подразумевает функционирование в условиях активного влияния внешних угроз, при ослаблении конкурентоспособности и необходимости реализации мер по возвращению к целевому состоянию экономической безопасности. При характеристике состояния экономической безопасности предприятия как переходного не будет происходить немедленных коренных изменений бизнес-структуры объекта, однако процессы стагнации возможны при отсутствии адекватных антикризисных мер. Нижней границей переходного состояния экономической безопасности будут являться вторые пороговые значения индикаторов. Третьим, кризисным классом состояний называют такое состояние экономической безопасности предприятия, при котором утеряна экономическая самостоятельность, способность противодействия проявлениям внешних и внутренних угроз [Виссарионов и др., 2017].

Общепринятые стандартные методы определения пороговых значений индикаторов (метод сопоставления с аналогичными российскими и зарубежными показателями, метод 
нормативного определения, экспертные опросы) неприемлемы для применения к объектам данного исследования, отличающимся структурной неоднородностью и специфическим набором индикаторов экономической безопасности.

Для выстраивания адекватной системы пороговых значений индикаторов экономической безопасности предлагается использовать совокупность математических и экспертных методов, позволяющих разделить классы состояния даже с учетом волатильности принятых к рассмотрению индикаторов. Роль эксперта в данном случае будет заключаться в первоначальной классификации значений индикаторов по классам состояний.

В качестве основного математического метода определения пороговых значений был использован метод ковариационного анализа, впервые предложенный группой российских исследователей для оценки энергетической безопасности регионов [Куклин и др., 2013]. С помощью метода ковариационного анализа для каждого индикатора необходимо определить два пороговых значения, разделяющих три класса состояния экономической безопасности: целевой $(Ц \kappa)$, переходный $(П \kappa)$ и кризисный $(К \kappa)$. В свою очередь переходный и кризисный классы равномерно разбиты на промежуточные подклассы состояний стабильный (Пк1 и Кк1) и угрожающий (Пк2 и Кк2).

1. Алгоритм определения пороговых значений индикаторов начинается с экспертной оценки сформированных выборок индикаторов - $\left(x_{i}\right)$. Для наблюдаемых количественных значений индикатора производится ранжирование, затем эксперты классифицируют эти значения по принадлежности к одному из трех классов состояния (Цк, Пк, Кк).

2. Для каждой подвыборки, распределенной в соответствующий класс состояния, вычисляются величины математического ожидания $\left(M_{Ц к}\left(x_{i}\right), M_{П к}\left(x_{i}\right), M_{К \kappa}\left(x_{i}\right)\right) \quad$ и среднеквадратического отклонения $\left(\sigma_{Ц \text { Цк }}\left(x_{i}\right), \sigma_{\text {Пк }}\left(x_{i}\right), \sigma_{\kappa \kappa}\left(x_{i}\right)\right)$.

3. Для двух пар классов (Цк $u$ Пк), (Пк, Кк) рассчитывается усредненное $\sigma$ по соответствующим подвыборкам.

4. Непосредственное пороговое значение между парой классов состояния (на примере Цк и Пк) вычисляется по формуле:

$$
x_{i(\text { ЦК-ПК })}=\frac{M_{\text {ЦК }}\left(x_{i}\right)+M_{П \kappa}\left(x_{i}\right)}{2}-\frac{\sigma^{2}}{M_{Ц К}\left(x_{i}\right)-M_{\Pi \kappa}\left(x_{i}\right)} * \ln \left(\frac{(1-p) * C_{12}}{p * C_{21}}\right),
$$

где $\sigma$ - среднее значение между двух среднеквадратических отклонений соответствующих классов состояния экономической безопасности, например $\sigma_{Ц \text { К }}\left(x_{i}\right)$ и $\sigma_{\text {Пк }}\left(x_{i}\right), p$ - плотность распределения вероятностей случайной величины, $C_{12}$ и $C_{21}$ - стоимости ошибок первого и второго рода соответственно.

Предлагаемый к использованию метод ковариационного анализа универсален, однако требует индивидуального экспертного мнения относительно пороговых значений каждого индикатора. Поскольку единицы измерения и масштабность у различных индикаторов разнятся, то в дальнейшем для совместной оценки нескольких индикаторов необходимо провести их нормирование.

На следующем этапе исследования проведена оценка значимости выбранных раннее угроз экономической безопасности. С помощью одной из передовых аналитических методик построения самосовершенствующихся моделей машинного обучения - для каждого предприятия была предпринята попытка оценки влияния набора факторных переменных (матрица $X$, размерности $m x f$, где $m$ - количество индикаторов, $f$ - длина ряда на целевую функцию (матрица $Y$, размерности $1 x f$ ) [Краковский и др., 2017]. Исследование было проведено в программной среде Jupyter Notebook на прикладном языке программирования Python.

Для реализации модели была выбрана методика ансамблевых алгоритмов, в частности, метод «bagging» [Breiman, 1994], позволяющий провести поиск зависимостей через формирование множества случайных обучающих выборок (набор индикаторов + целевая функция), результаты которых, впоследствии, усредняются, чем достигается повышение 
качества и точности анализа [Elliott, Granger, Timmermann, 2013]. Базовый алгоритм, опираясь на подмножество обучающих матриц (вида $X_{i}$, размерности $m x g$, где $g<f$, формируются случайным порядком из $X)$, добивается построения таких предикторов $D_{i}\left(m, X_{i}\right)$ для поиска максимального количества соответствий (положительных ответов), чтобы добиться минимизации потерь качества объяснения целевой функции [Polikar, 2006].

Результатом модели для каждого объекта исследования является сформированная матрица $Y r$, в которую входят только значимые группы угроз, влияющие на целевой показатель компании, и количественное выражение значимости (может принимать значение на отрезке [0;1], суммарное значение будет равно единице). Критерием оценки качества полученных зависимостей была выбрана метрика $R^{2}$ (коэффициент детерминации), отражающая суммарную долю дисперсий рассматриваемых факторов [Чернышова и др., 2019]. Агрегированные результаты моделирования приведены в таблице 3.

Таблица 3

Table 3

Значимость групп угроз экономической безопасности металлургических предприятий, доля

Significance of groups of threats to economic security metallurgical enterprises, share

\begin{tabular}{|c|c|c|c|c|c|}
\hline \multirow{2}{*}{$\begin{array}{c}\text { Источник } \\
\text { угроз } \\
\text { экономической } \\
\text { безопасности }\end{array}$} & \multirow{2}{*}{$\begin{array}{c}\text { Группы угроз } \\
\text { экономической } \\
\text { безопасности }\end{array}$} & \multicolumn{4}{|c|}{ Объекты исследования } \\
\hline & & $\begin{array}{c}\text { ПАО } \\
\text { «MMК» }\end{array}$ & $\begin{array}{c}\text { ПАО } \\
\text { «НЛМК» }\end{array}$ & $\begin{array}{c}\text { ПАО } \\
\text { «Северсталь» }\end{array}$ & $\begin{array}{c}\text { ПАО } \\
\text { «ЕВРА» }\end{array}$ \\
\hline \multirow{6}{*}{$\begin{array}{l}\text { Внешние } \\
\text { угрозы }\end{array}$} & $\begin{array}{l}\text { Политико- } \\
\text { экономические } \\
\text { (мегауровень) }\end{array}$ & $7,4 \%$ & $9,3 \%$ & $13,5 \%$ & $13,9 \%$ \\
\hline & $\begin{array}{l}\text { Внешнерыночные } \\
\text { (международный } \\
\text { уровень) }\end{array}$ & $13,7 \%$ & $16,7 \%$ & $7,1 \%$ & $11,1 \%$ \\
\hline & $\begin{array}{l}\text { Политические } \\
\text { (международный } \\
\text { уровень) }\end{array}$ & $2,1 \%$ & $4,9 \%$ & $3,9 \%$ & $6,7 \%$ \\
\hline & $\begin{array}{l}\text { Внутрирыночные } \\
\text { (макроэкономический } \\
\text { уровень }\end{array}$ & $11,4 \%$ & $12 \%$ & $11,5 \%$ & $12,4 \%$ \\
\hline & $\begin{array}{l}\text { Нормативно- } \\
\text { законодательные } \\
\text { (макроэкономический } \\
\text { уровень) }\end{array}$ & $6,3 \%$ & $7,1 \%$ & $8,3 \%$ & $9,8 \%$ \\
\hline & $\begin{array}{l}\text { Потребительские } \\
\text { (макроэкономический } \\
\text { уровень) }\end{array}$ & $1 \%$ & $1 \%$ & $1 \%$ & $1 \%$ \\
\hline & $\begin{array}{l}\text { Социальные } \\
\text { (мезоэкономический } \\
\text { уровень) }\end{array}$ & $3 \%$ & $2 \%$ & $2 \%$ & $3 \%$ \\
\hline & $\begin{array}{l}\text { Информационные } \\
\text { (мезо- и } \\
\text { микроэкономический } \\
\text { уровни) }\end{array}$ & $1 \%$ & $1 \%$ & $1 \%$ & $1 \%$ \\
\hline & $\begin{array}{l}\text { Экологические (мезо- } \\
\text { и микроэкономи- } \\
\text { ческий уровни) }\end{array}$ & $4 \%$ & $4 \%$ & $3 \%$ & $3 \%$ \\
\hline
\end{tabular}




\begin{tabular}{|c|c|c|c|c|c|}
\hline \multirow{2}{*}{$\begin{array}{c}\text { Источник } \\
\text { угроз } \\
\text { экономической } \\
\text { безопасности }\end{array}$} & \multirow{2}{*}{$\begin{array}{c}\text { Группы угроз } \\
\text { экономической } \\
\text { безопасности }\end{array}$} & \multicolumn{4}{|c|}{ Объекты исследования } \\
\hline & & $\begin{array}{c}\text { ПАО } \\
\text { «MМК» }\end{array}$ & $\begin{array}{c}\text { ПАО } \\
\text { «НЛМК» }\end{array}$ & $\begin{array}{c}\text { ПАО } \\
\text { «Северсталь» }\end{array}$ & $\begin{array}{c}\text { ПАО } \\
\text { «ЕВРАЗ» }\end{array}$ \\
\hline \multirow{4}{*}{$\begin{array}{l}\text { Внутренние } \\
\text { угрозы }\end{array}$} & $\begin{array}{l}\text { Инвестиционные } \\
\text { (микроэкономический } \\
\text { уровень) }\end{array}$ & $9,5 \%$ & $7,5 \%$ & $13,4 \%$ & $15,2 \%$ \\
\hline & $\begin{array}{l}\text { Финансово- } \\
\text { управленческие } \\
\text { (микроэкономический } \\
\text { уровень) }\end{array}$ & $14,8 \%$ & $8,4 \%$ & $21,2 \%$ & $14,6 \%$ \\
\hline & $\begin{array}{l}\text { Производственно- } \\
\text { сбытовые } \\
\text { (микроэкономический } \\
\text { уровень) }\end{array}$ & $22,8 \%$ & $22,1 \%$ & $12,1 \%$ & $6,3 \%$ \\
\hline & $\begin{array}{l}\text { Управленческие } \\
\text { (миниэкономический } \\
\text { уровень) }\end{array}$ & $3 \%$ & $4 \%$ & $2 \%$ & $2 \%$ \\
\hline \multicolumn{2}{|c|}{ Коэффициент детерминации $R^{2}$} & $98 \%$ & $97 \%$ & $95 \%$ & $99 \%$ \\
\hline
\end{tabular}

Рассчитано авторами

\section{Заключение}

По итогам моделирования значимости групп угроз экономической безопасности можно отметить, что для металлургических предприятий в качестве наиболее важных угроз выделен спектр финансово-экономических, технико-технологических и маркетинговых угроз, являющихся эндогенными, а также экзогенные внутри- и внешнерыночные угрозы. Каждый из рассмотренных объектов исследования обладает своей индивидуальной спецификой, в связи с чем некоторые группы угроз характерны только одному или двум предприятиям. Такой результат не должен позволить полностью исключить из рассмотрения и мониторинга менее значимые угрозы. В дальнейшем знание спектра основных угроз и степени их влияния на предприятия черной металлургии поможет создать комплексную нечетко-логическую модель оценки экономической безопасности и позволит, зная примерные тенденции, выносить прогнозные сценарные планы развития бизнеса.

\section{Список литературы}

1. Виссарионов А.Б., Гумеров Р.Р. 2017. Об использовании предельных (пороговых) значений индикаторов экономической безопасности Российской Федерации. Управленческие науки, 3: 12-20.

2. Глазьев С.Ю. 1997. Основа обеспечения экономической безопасности страны альтернативный реформационный курс. Российский экономический журнал, 1-2: 3

3. Калина А.В., Савельева И.П. 2014. Формирование пороговых значений индикативных показателей экономической безопасности России и ее регионов. Вестник Южно-уральского государственного университета. Серия: Экономика и менеджмент, 4: 15-24.

4. Краковский Ю.М., Лузгин А.Н. 2017. Исследование современных методов построения прогнозирующих ансамблей применительно к задаче интервального прогнозирования. Современные технологии. Системный анализ. Моделирование, 3 (55): 94-101.

5. Куклин А.А., Мызин А.Л., Пыхов П.А., Потанин М.М. 2013. Диагностика и механизмы повышения энергетической безопасности России. Вестник Забайкальского государственного университета, 10 (101): 134-149.

6. Магомедов О.А. 2008. Методологические принципы оценки состояния экономической безопасности региона. Проблемы экономики и юридической практики, 3: 246-248.

7. Материалы Федеральной службы государственной статистики. Показатели для оценки состояния экономической безопасности России. URL: https://www.gks.ru/econSafety (дата обращения 25.05.2020). 
8. Сенчагов В.К., Иванов Е.А. 2015. Структура механизма современного мониторинга экономической безопасности России. М.: Институт экономики РАН, 46 с.

9. Сенчагов В.К., Максимов Ю.М., Митяков С.Н., Митякова О.И. 2011. Инновационные преобразования как императив экономической безопасности региона: система индикаторов. Инновации, 5: 56-61.

10. Симонов С.Г., Ямова О.В. 2018. Критерии и показатели оценки уровня экономической безопасности крупных компаний нефтегазового профиля. Вестник Омского университета. Серия «Экономика», 4 (64): 57-67.

11. Указ Президента РФ от 13.05.2017 г. № 208 «О Стратегии экономической безопасности Российской Федерации на период до 2030 года». URL: https://www.garant.ru/products/ipo/prime/doc/ 71572608/ (дата обращения 25.05.2020).

12. Чернышова Г.Ю., Самаркина Е.А. 2019. Методы интеллектуального анализа данных для прогнозирования финансовых временных рядов. Известия Саратовского университета. Новая серия. Серия Экономика. Управление. Право, 2: 181-188.

13. Breiman L. 1994. Bagging Predictors. Technical Report, 421. URL: https://www.stat.berkeley.edu/ breiman/bagging.pdf (дата обращения 25.05.2020)

14. Elliott G., Granger C., Timmermann A. 2013.Handbook of Economic Forecasting, 2: 1324.

15. Polikar R. 2006. Ensemble based systems in decision making. IEEE Circuits and Systems Magazine, 6 (3): 21-45.

\section{References}

1. Vissarionov A.B., Gumerov R.R. 2017. On the use of limit (threshold) values of indicators of economic security of the Russian Federation. Management Sciences, 3: 12-20.

2. Glazyev S.Y. 1997. The basis for ensuring the country's economic security is an alternative reformation course. Russian economic journal, 1-2: 3

3. Kalina A.V., Savelieva I.P. 2014. Formation of threshold values for indicative indicators of economic security in Russia and its regions. Bulletin of the South Ural state University. Series: Economics and management, 4: 15-24.

4. Krakovsky Y.M., Luzgin A.N. 2017. The study of current methods for constructing ensembles of prediction as applied to the problem of interval prediction. Modern technology. System analysis. Modeling, 3 (55): 94-101.

5. Kuklin A.A., Myzin A.L., Pykhov P.A., Potanin M.M. 2013. Diagnostics and mechanisms for improving Russia's energy security. Bulletin of the TRANS-Baikal state University, 10 (101): 134-149.

6. Magomedov O.A. 2008. Methodological principles for assessing the state of economic security in the region. Problems of Economics and legal practice, 3: 246-248.

7. Materials of the Federal state statistics service. Indicators for assessing the state of Russia's economic security. URL: https://www.gks.ru/econSafety (accessed 25.05.2020).

8. Senchagov V.K., Ivanov E.A. 2015. Structure of the mechanism of modern monitoring of economic security in Russia. Moscow: Institute of Economics of the Russian Academy of Sciences, $46 \mathrm{p}$.

9. Senchagov V.K., Maximov Y.M., Mityakov S.N., Mityakova O.I. 2011. Innovative transformations as an imperative of economic security in the region: a system of indicators. Innovation, 5: 56-61.

10. Simonov S.G., Yamova O.V. 2018. Criteria and indicators for assessing the level of economic security of large oil and gas companies. Bulletin of Omsk University. Economics Series, 4 (64): 57-67.

11. Decree of the President of the Russian Federation dated 13.05.2017 No. 208 «On the Strategy of economic security of the Russian Federation for the period up to 2030». URL: https://www.garant.ru/products/ipo/prime/doc/71572608/ (accessed 25.05.2020).

12. Chernyshova G.Y., Samarkina E.A. 2019. Data mining methods for predicting financial time series. Izvestiya of Saratov University. New series. The Economic Series. Management. Law, 2: 181-188.

13. Breiman L. 1994. Baggy Predictors. Technical Report, 421. URL: https://www.stat.berkeley.edu/ breiman / bagging. pdf (accessed 25.05.2020)

14. Elliott G., Granger C., Timmermann A. 2013.Handbook of economic forecasting, 2: 1324.

15. Polikar R. 2006. Ensemble systems in the decision-making process. Magazine IEEE Circuits and Systems Magazine, 6 (3): 21-45. 


\section{ИНФОРМАЦИЯ ОБ АВТОРАХ}

Рябков Илья Леонидович, аспирант Череповецкого государственного университета, Череповец, Россия

Яшалова Наталья Николаевна, доктор Natal'ya N. YAshalova, Doctor of Economics, экономических наук, доцент, заведующая кафедрой экономики и управления Череповецкого государственного

Череповец, Россия

\section{INFORMATION ABOUT THE AUTHORS}

Il'ya L. Ryabkov, Postgraduate Student of Cherepovets State University, Cherepovets, Russia Associate Professor, Head of the Department of Economics and Management of Cherepovets State

\author{
университета, University, Cherepovets, Russia
}

